\title{
XLV. \\ Ueber eine vortheilhafte Methode, das Jod selbst aus den verdünntesten Lösungen \\ zu gewinnen.
}

Von

J. Persos.

(Journ. de Pharm. et de Chim. XII, 105̆.)

Heutzutage wird das Jor so hăufig in der Medicin angewendet, dass der Preis dieses Körpers immer höher steigt; mehr als jemals lüblt man deshalb das Bedürfniss, das Jod mit der grössten Oekononie aus allen jodhaltigen Mineralwässern, aus künstlichen Bälern, in welche man Jod brachte, und endlich auch aus dem Urin von Kranken, die Jod einnehmen, zu gewinnen.

Soubeiran, welcher das vor ihm befolgte Verfahren, das Jod aus den Mutterlaugen der Varecsoda abzuscheiden, zu kostspielig und $z u$ sehr zeitraubend fand, schlug vor, diesen Körper mit schwefelsaurem Kupferoxyd zu fällen, welchem er als reducirendes Element elwas Eisenfeile zuselzte, um das Kupferjodid in Kupferjodür zu verwandeln.

Später ersetzte man, um zu demselben Resultat zu gelangen, das Eisen durch schwefelsaures Eisenoxydul.

Die schwankenden Resultate, die man nach dem einen wie nach dem andern dieser Verfahren erhält, musste Allen auffallen, die sie angewendet hatten; es war daher ganz natürlich, eine bessere Methode aufzusuchen. Labiche und Chantrel (Revue scientifique $X X V, 279$ ) stellten ein Verfahren auf, das auf der Unlöslichkeit der Jodstärke beruhte; da sich aber das Jod nur im freien Zustande mit der Stärke verbindet, so bedarf man der Dazwischenkunlt des Chlors, um ersteres aus den Salzverbindungen frei zu machen; darin liegt aber ein unübersteigbares Hinderniss für die Anwendung dieser Yethode im Grossen.

Znr Erledigung dieser Frage veranlasst, zeigte ich zuerst, Jass das essigsature Eisenoxydul, anstatt des schwefelsauren Salzes angewendet, eine schnellere Reduction bewirkt; da aber in 
Folge des Einflusses der Mengen der angewendeten Flüssigkeiten auf eine regelmåssige Fällung des Kupferjodürs nicht zu rechnen ist, so nahm ich zur schwefligen Säure meine Zuflucht, deren reducirende Wirkung auf das Kupferoxyd Chevreul kennen lehrte.

Einige Worte werden ausreichen, die Reaction zu verstehen.

Wenn man 1 Gramme schwefelsaures Kupferoxyd in $150 \mathrm{Cb} . \mathrm{C}$. Wasser löst und zu der Auflösung 1 Gramme schwefligsaures Natron bringt, so färbt sich die Flüssigkeit grün und trübt sich endlich in Folge doppelter Zersetzung.

Da es vortheilhaft ist, einen Niederschlag zu vermeiden und zu gleicher Zeit die Flüssigkeit zu entfärben, so giesst man die nöthige Menge schwefliger Säure hinzu und darauf einen Tropfen einer Jodkaliumlösung; sogleich wird die Flüssigkeit opalisirend, darauf milchig und trübt sich immer mehr, bis sich nach Verlauf einer Stunde ein weisser, leicht rosenrother Niederschlag von Kupferjodür gebildet hat. Durch Sieden der Flüssigkeit erhält inan den Niederschlag in wenigen Minuten und trennt die Flüssigkeil davon durch blosses Decantiren.

Um jodhaltige Wässer zu behandeln, leitet man schwefligsaures Gas hindurch, bis das Wasser darnach riecht, damit alles Jod, welches sich als jodsaure Verbindung in der Flüssigkeit befinden sollte, in Jodwasserstoffsăure verwandelt werde, der Bildung desNiederschlags ferner, der durch wechselseitige Einwirkung des schwefligsauren Natrons und des schwefelsauren Kupferoxydes entsteht, vorzubeugen, und endlich die Reduction des Kupferoxydes zu bewirken.

Darauf löst man nach und nach in der Flüssigkeit einen Theil schwefelsaures Kupferoxyd und einen Theil zweifachschwefligsaures Natron, wobei man annähernd die Menge des erstern nach der angenommenen Quantităt Jod in der Flüssigkeit so berechnet, dass man ungefähr 3 Theile schwefelsaures Kupferoxyd auf einen Theil Jodkalium oder Jodnatrium nimmt. Endlich stellt man die Flüssigkeit hin oder lässt sie sieden, je nachdem man den Niederschlag. sogleich oder erst nach einigen Stunden wünscht.

Lässt man den Niederschlag in conischen Gefässen sich bilden, so kann er leicht auf ein kleines Volumen concentrirt werden. In allen Fällen sammelt man ihn auf einem Filter, wäscht ihn aus, trocknet und extrahirt das Jod nach einem oder dem 
andern der bekannten Verfahren. Besonders vortheilhaft ist die Methode, nach welcher das vorher mit 2 Aequivalenten Mangansuperoxyd gemengte Kupferjodür geglüht wird.

Die beschriebene Reaction lässt sich so leicht ausführen, dass von nun an alle jodhaltigen Wăsser, selbst die schwächsten, nach dieser Methode behandelt werden können. Ohne Zweilel lässt sie sich auch bei der Analyse brom - und jodhaltiger Mineralwässer anwenden.

\section{XLVl. \\ Beiträge zur Chemie der Platinmetalle. \\ C. Cans.}

(Bullet. de. St. Pétersbourg)

Bei der Untersuchung des Platinrückstandes hatte ich Gelegenheit, mehrere bisher nuch nicht beobachtete Reactionen der Platinmetalle und ihrer Verbindungen wahrsunelmen, welche meine Aufmerksamkeit in hohem Grade anregten, deren genaueres Studium ich jedoch bis auf gelegenere Zeit aufschieben musste, da die Untersuchung des Rutheniums mich gänzlich in Anspruch nahm. Nachdem ich meine Arbeit über die Fundamentalverbindungen dieses Metalles beendigt hatte, ging ich zur Erürterung jener Reactionen über und theile hier vorlāufig einige Thatsachen mit, welche, wie ich boffe, wohl einige Beachtung verdienen.

\section{Ueber das Verhalten des Iridiumchlorides zu dem salpetersauren Silberoxyde.}

Es ist eine bekannte Thatsache. dass das Chlor aus den Lösungen der Chloride der verschiedenen Platinmetalle nicht durch salpetersaures Silberoxyd als reines Chlorsilber gefällt werden kann, weil ein Intheil des unzersetzten Chlorides in Verbindung mit dem Chlorsiller niedergeschlagen wird; dass man daher bei der Analyse tlieser Verbindungen sie zuvor durch Alkalieu zer- 